\title{
Deformation Mechanism and Hot Workability of Extruded Magnesium Alloy AZ31
}

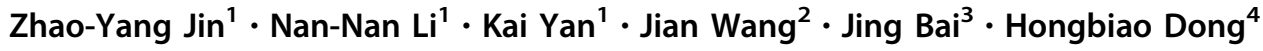

Received: 10 October 2017/Revised: 1 November 2017/ Published online: 30 November 2017

(C) The Chinese Society for Metals and Springer-Verlag GmbH Germany, part of Springer Nature 2017

\begin{abstract}
Using the flow stress curves obtained by Gleeble thermo-mechanical testing, the processing map of extruded magnesium alloy AZ31 was established to analyze the hot workability. Stress exponent and activation energy were calculated to characterize the deformation mechanism. Then, the effects of hot deformation parameters on deformation mechanism, microstructure evolution and hot workability of AZ31 alloy were discussed. With increasing deformation temperature, the operation of non-basal slip systems and full development of dynamic recrystallization (DRX) contribute to effective improvement in hot workability of AZ31 alloy. The influences of strain rate and strain are complex. When temperature exceeds $350{ }^{\circ} \mathrm{C}$, the deformation mechanism is slightly dependent of the strain rate or strain. The dominant mechanism is dislocation cross-slip, which favors DRX nucleation and grain growth and thus leads to good plasticity. At low temperature (below $350{ }^{\circ} \mathrm{C}$ ), the deformation mechanism is sensitive to strain and strain rate. Both the dominant deformation mechanism and inadequate development of DRX deteriorate the ductility of AZ31 alloy. The flow instability mainly occurs in the vicinity of $250^{\circ} \mathrm{C}$ and $1 \mathrm{~s}^{-1}$.
\end{abstract}

Keywords Hot workability · Deformation mechanism · Dynamic recrystallization · Activation energy · Magnesium alloy

\section{Introduction}

Magnesium (Mg) alloys have been widely used in automotive, aerospace and electronics industries owing to their low density, high specific strength and good electromagnetic shielding [1]. Owing to high strength and good ductility, aluminum-zinc (AZ) series of Mg alloys, such as AZ31, can be rolled, extruded and forged into a variety of sheets, profiles and pipes [2]. However, having a hexagonal

Available online at http://link.springer.com/journal/40195

Zhao-Yang Jin

zyjin@yzu.edu.cn

1 School of Mechanical Engineering, Yangzhou University, Yangzhou 225127, China

2 School of Physics and Optoelectronic Engineering, Nanjing University of Information Science and Technology, Nanjing 210044, China

3 School of Materials Science and Engineering, Southeast University, Nanjing 211189, China

4 Department of Engineering, University of Leicester, Leicester LE1 7RH, England close-packed (hcp) structure, AZ31 alloy exhibits a narrow window of plastic formability and is sensitive to the deformation temperature and strain rate. The deformation mechanisms of $\mathrm{Mg}$ alloys vary with the deformation conditions, which subsequently has a direct influence on the kinetics during the microstructure evolution and then hot workability of $\mathrm{Mg}$ alloys [3, 4]. Therefore, it is of great scientific and engineering significance to understand and explore the inherent relationship between deformation mechanism, microstructure evolution and plastic workability.

So far, studies on deformation mechanism, microstructure evolution and plastic formability of $\mathrm{Mg}$ alloys are usually independent of each other. Some scholars studied the influence of deformation conditions on the deformation mechanism through calculating the values of stress exponent $n$ and activation energy $Q$ [5]. On microstructure evolution and hot workability during plastic deformation, many scholars adopted processing map based on dynamic material model to study the hot deformation behavior [6-10]. Effects of grain size [11], homogenization [12] and deformation texture [13] on the workability of $\mathrm{Mg}$ alloy AZ31 were also investigated by the processing map. Some 
scholars attempted to combine the processing map and material constants mentioned above to analyze the deformation behavior of $\mathrm{Mg}$ alloys. Srinivasan et al. established the processing map of $\mathrm{Mg}-3 \mathrm{Al}$ alloy (wt\%) at a true strain of 0.5 , calculated the value of $n$ and $Q$ in a flow instability regime and a peak efficiency of power dissipation regime and then analyzed the deformation mechanisms of $\mathrm{Mg}-3 \mathrm{Al}$ alloy in those above-mentioned typical domains [14]. Peng et al. [15] studied the hot deformation behavior of as-rolled AZ31 alloy in different domains of processing map.

Considering the occurrence of dynamic recrystallization (DRX) during the hot deformation for $\mathrm{Mg}$ alloys, the deformation mechanism is not only related to the pretreatment state of materials, deformation temperature and strain rate, but also to the strain and the microstructure evolution during deformation. In this work, a correlation model between stress exponent, deformation activation energy, hot workability and processing parameters (i.e., deformation temperature, strain rate and strain) was established for as-extruded Mg alloy AZ31. Furthermore, the influence of processing parameters on deformation mechanism, microstructure evolution and workability was discussed.

\section{Experimental}

A commercial $\mathrm{Mg}$ alloy AZ31 ingot with chemical composition of $2.8 \mathrm{wt} \% \mathrm{Al}, 1.26 \mathrm{wt} \% \mathrm{Zn}$ and $\mathrm{Mg}$ in balance was used as raw material. After smelting, homogenization and pre-extrusion treatments, it was machined into $\Phi 10 \mathrm{~mm} \times 15 \mathrm{~mm}$ cylindrical samples. Isothermal compression tests were carried out on a Gleeble-1500 thermomechanical simulator. To ensure uniform deformation of the specimens, a graphite flake was placed at both ends of the samples to reduce the friction between specimens and die. During the experiments, the samples were heated to certain experimental temperature at a heating rate of $5{ }^{\circ} \mathrm{C} \mathrm{s}^{-1}$, held for $180 \mathrm{~s}$ and then compressed. Maximum true strain was set as 0.9 . The experimental temperature varied from 250 to $400{ }^{\circ} \mathrm{C}$, and the experimental strain rate range is from 0.001 to $1 \mathrm{~s}^{-1}$. After compression, the samples were immediately quenched in water to maintain the deformation microstructure. Both the as-extruded and the compressed specimens were cut along the longitudinal direction, and the microstructure on the axial section was observed by the Leica DMI3000 M optical microscope (OM) and the Zeiss Supra 55 field emission scanning electron microscope (SEM). The metallurgical samples were prepared by grinding with 1200 grit $\mathrm{SiC}$ papers and then were polished down to $1 \mu \mathrm{m}$ surface finish. Finally, samples were etched with solution containing $1 \mathrm{~g}$ of oxalic acid, $1 \mathrm{ml}$ of acetic acid, $1 \mathrm{ml}$ of nitric acid prior to metallographic observation. The samples for SEM examination were prepared similarly but without etching.

The initial microstructure of AZ31 is shown in Fig. 1. Average grain size of $15.3 \mu \mathrm{m}$ was obtained from the OM images by the linear intercept method as shown in Fig. 1a. In Fig. 1b, SEM image shows that there are a large number of second phases in the as-extruded samples.

The true stress-strain curves of Mg alloy AZ31 obtained by hot compression are shown in Fig. 2, which exhibit a typical flow stress curves of dynamic recrystallization. At the beginning of the deformation, the flow stress increased rapidly due to work hardening [16]. For the low stacking fault energy, the dislocations were multiplied with the increasing strain, which led to the dynamic recrystallization nucleation and grain growth when the dislocation density increased to the critical value [17]. The newly formed DRX grains were of low dislocation density and of no distortion. With a continuous increase in strain, the dynamic softening effect was gradually enhanced and the rate of the increase in flow stress was slow down. After reaching the peak stress, the flow stress decreased and tended to be stable. At this point, the work hardening and dynamic softening approached to an equilibrium. However, fluctuations of flow stress were observed as deformed at $400{ }^{\circ} \mathrm{C}$ and $0.001 \mathrm{~s}^{-1}$. This may be ascribed to a high rate of nucleation and grain boundary migration at high temperature and low strain rate, leading to sudden drop in flow stress and thus the occurrence of fluctuation as combined with work hardening effect.

\section{Establishment of Processing Map}

The processing map established by Prasad et al. [18] is based on dynamic materials model and is the superimposition of power dissipation map and flow instability map. The power dissipation map reflects the power dissipation due to microstructure evolution, while the flow instability map provides the domain where it is likely to incur instability defects such as shear bands and cracks. For the bulk plastic forming process, such as forging, rolling and extrusion, processing map can predict an excellent workability domain, and it is thus useful for process optimization [19].

In the dynamic materials model, materials are considered as a power dissipater. The power dissipation per volume $P$ consists of two parts: (1) $G$, power dissipation due to plastic deformation, large part of which transfers into heat by viscoplastic deformation; and (2) $J$, power dissipation induced by the microstructure evolution during deformation [18]. $P, G$ and $J$ can be calculated through flow stress curve: 

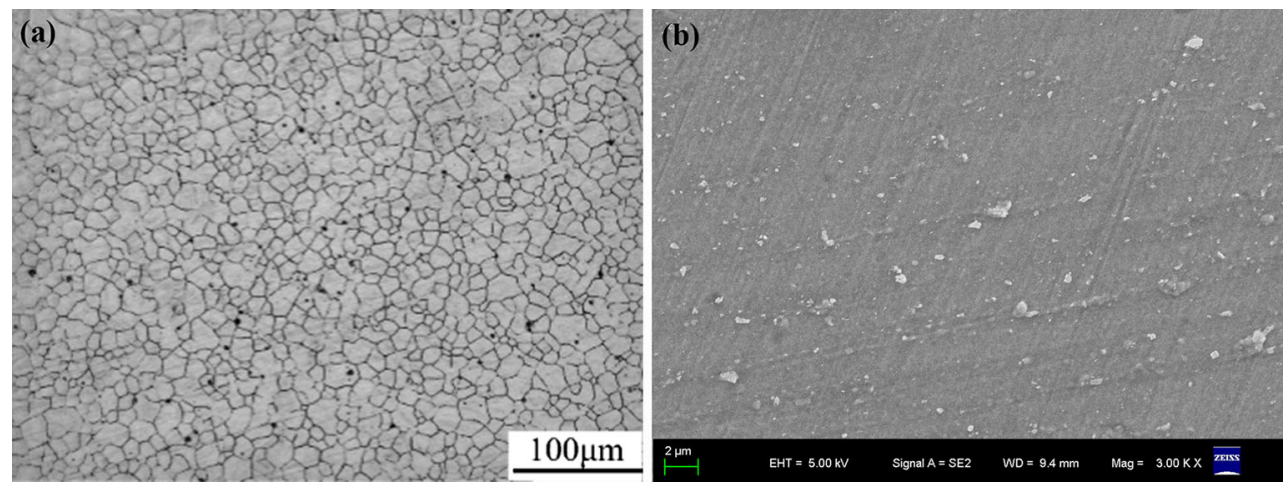

Fig. 1 OM a and SEM b morphologies of extruded AZ31 magnesium alloy
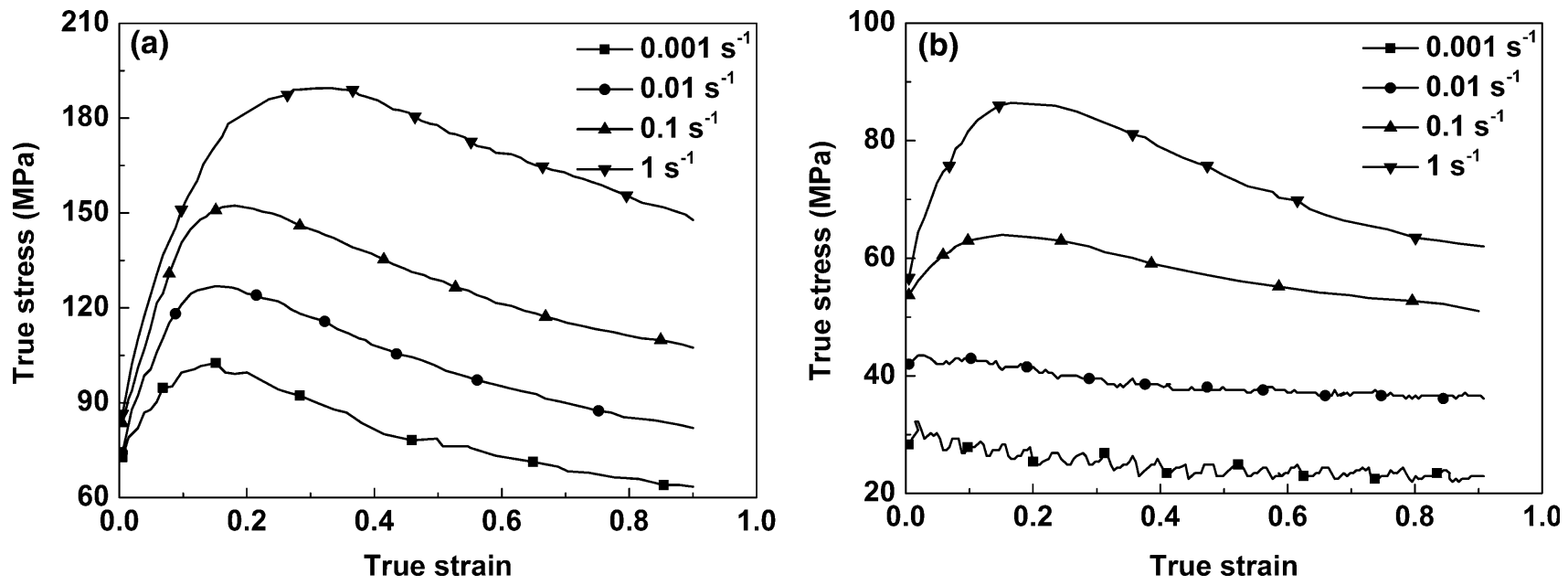

Fig. 2 True stress-strain curves of AZ31 magnesium alloy at $250{ }^{\circ} \mathrm{C}$ a, $400{ }^{\circ} \mathrm{C} \mathbf{b}$

$P=\sigma \dot{\varepsilon}=G+J=\int_{0}^{\dot{\varepsilon}} \sigma \mathrm{d} \dot{\varepsilon}+\int_{0}^{\sigma} \dot{\varepsilon} \mathrm{d} \sigma$,

where $\sigma$ is the flow stress, $\dot{\varepsilon}$ is the strain rate. At a given temperature $T$ and strain $\varepsilon$, the ratio of $G$ and $J$ is determined by the strain rate sensitivity of the flow stress, i.e., $m$, defined as:

$m=\frac{\partial J}{\partial G}=\frac{\dot{\varepsilon} \mathrm{d} \sigma}{\sigma \mathrm{d} \dot{\varepsilon}}=\left(\frac{\partial \ln \sigma}{\partial \ln \dot{\varepsilon}}\right)_{T, \varepsilon}$.

For pure metal, $m$ is independent of $T$ and $\dot{\varepsilon}$, while a function of $T$ and $\dot{\varepsilon}$ for alloys [20].

Prasad et al. [18] proposed a dimensionless parameter, i.e., efficiency of power dissipation $\eta$, to represents the dissipating ability of the workpiece as normalized with respect to the total power input to the system. $\eta$ is the ratio of the nonlinear power dissipation to the linear power dissipation in the deformed material and can be expressed as:
$\eta=\frac{J}{J_{\max }}=\frac{P-G}{P / 2}$

when $m=1$, the material is in a linear dissipated state, and $J$ reaches its maximum $J_{\max }=\sigma \dot{\varepsilon} / 2=P / 2$. Substituting Eq. (1) into Eq. (3), it obtains:

$\eta=\frac{2\left(\sigma \dot{\varepsilon}-\int_{0}^{\dot{\varepsilon}} \sigma \mathrm{d} \dot{\varepsilon}\right)}{\sigma \dot{\varepsilon}}$.

When $\eta$ is calculated by Eq. (4), the integral term used to calculate $G$ should be accounted from the strain rate of 0 , which, however, cannot be obtained by experiment. To overcome the issue, Murty et al. [21] transformed the integration of $G$ into:

$G=\int_{0}^{\dot{\varepsilon}} \sigma \mathrm{d} \dot{\varepsilon}=\int_{0}^{\dot{\varepsilon}_{\min }} \sigma \mathrm{d} \dot{\varepsilon}+\int_{\dot{\varepsilon}_{\min }}^{\dot{\varepsilon}} \sigma \mathrm{d} \dot{\varepsilon}$,

where $\dot{\varepsilon}_{\text {min }}$ is the minimum strain rate of the experimental test. To calculate the first term on the right side of Eq. (5), it is assumed that the constitutive relation of the material 
fits the power function relation, i.e., $\sigma=k \dot{\varepsilon}^{m}$ [22], and then Eq. (4) can be re-expressed as:

$\eta=\frac{2\left(\sigma \dot{\varepsilon}-\int_{0}^{\dot{\varepsilon}} \sigma \mathrm{d} \dot{\varepsilon}\right)}{\sigma \dot{\varepsilon}}=\frac{2\left(\sigma \dot{\varepsilon}-\left(\frac{\sigma \dot{\varepsilon}_{\min }}{m+1}+\int_{\dot{\varepsilon}_{\min }}^{\dot{\varepsilon}} \sigma \mathrm{d} \dot{\varepsilon}\right)\right)}{\sigma \dot{\varepsilon}}$.

Meanwhile, Murty et al. proposed the instability criterion which is applicable for any kinds of flow stress curves based on dynamic materials model. This instability criterion is expressed as:

$2 m-\eta<0$ or $\eta \leq 0$.

In this work, Eqs. (6) and (7) were used to calculate the power dissipation efficiency and the flow instability parameter. The map showing the variation of $\eta$ with $T$ and $\dot{\varepsilon}$ is the power dissipation map, and that showing the flow instability parameter $\zeta$ [the left-hand side of Eq. (7)] with $T$ and $\dot{\varepsilon}$ is the flow instability map. On the two-dimensional map of $T$ and $\dot{\varepsilon}$, superimposing the power dissipation map and the flow instability map obtains the processing map.

Figure 3 shows the processing map of Mg alloy AZ31 at different strains. The shaded part represents the flow instability regime, the grid filled part represents the peak efficiency of power dissipation area, and the value of the contour represents the efficiency of power dissipation, respectively. As shown in Fig. 3a, there is an instability regime when strain equals to 0.2 , which locates at low temperature and high strain rate zone (Domain I). When the strain is higher than 0.2 , the instability regime disappears and the processing maps under different strains are similar (Fig. 3b). The efficiency of power dissipation increases with either increasing temperature or decreasing strain rate, and thus, the peak efficiency of power dissipation is located at high temperature and low strain rate. The efficiency of power dissipation is related to microstructure evolution. Generally, a high efficiency of power dissipation indicates dynamic recovery or dynamic

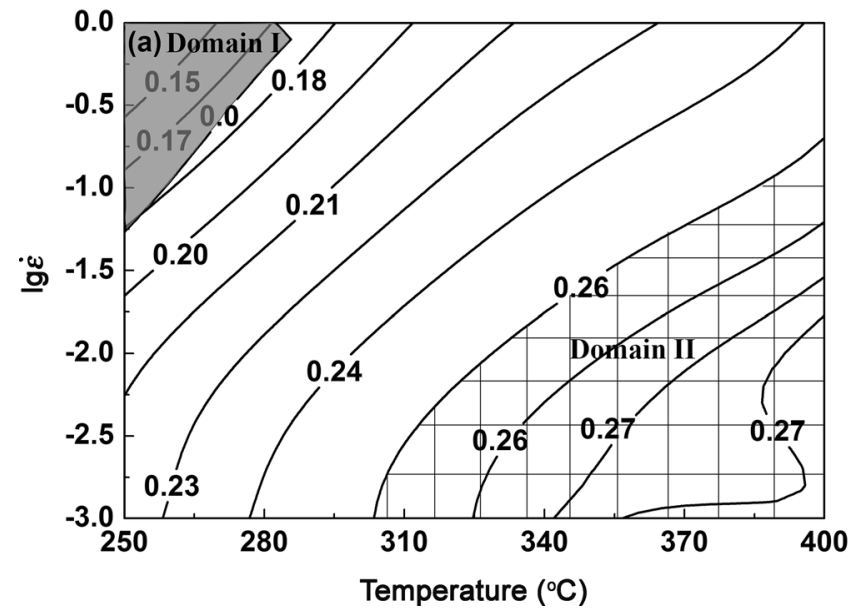

Fig. 3 Processing maps of AZ31 alloy at strains of 0.2 a, $0.4 \mathbf{b}$ recrystallization [23]. However, when the efficiency of power dissipation is greater than $50 \%$, it may be due to the initiation of crack [14].

\section{Calculation of Stress Exponent and Activation Energy}

\subsection{Values of $n$ and $Q$ Under a Constant Strain}

Stress exponent $n$ and deformation activation energy $Q$ are two important parameters which characterize the deformation mechanism and can be calculated from flow stress curves. According to Fig. 2, the flow stress of Mg alloy AZ31 at high temperature is relevant to temperature, strain rate and strain. In general, the relationship between flow stress, temperature and strain rate can be expressed by a hyperbolic sine function [24]:

$\dot{\varepsilon} \exp \left(\frac{Q}{R T}\right)=A[\sinh (\alpha \sigma)]^{n}$,

where $A$ and $\alpha$ are material constants, $R$ is the gas constant. Taking the natural logarithm for both sides of Eq. (8), it obtains:

$\ln \dot{\varepsilon}+\frac{Q}{R T}=\ln A+n \ln [\sinh (\alpha \sigma)]$.

When temperature is constant, $n$ can be calculated by the expression as follows:

$n=\left.\frac{\partial \ln \dot{\varepsilon}}{\partial \ln [\sinh (\alpha \sigma)]}\right|_{T}$.

When strain rate is constant, $Q /(n R)$ is calculated as:

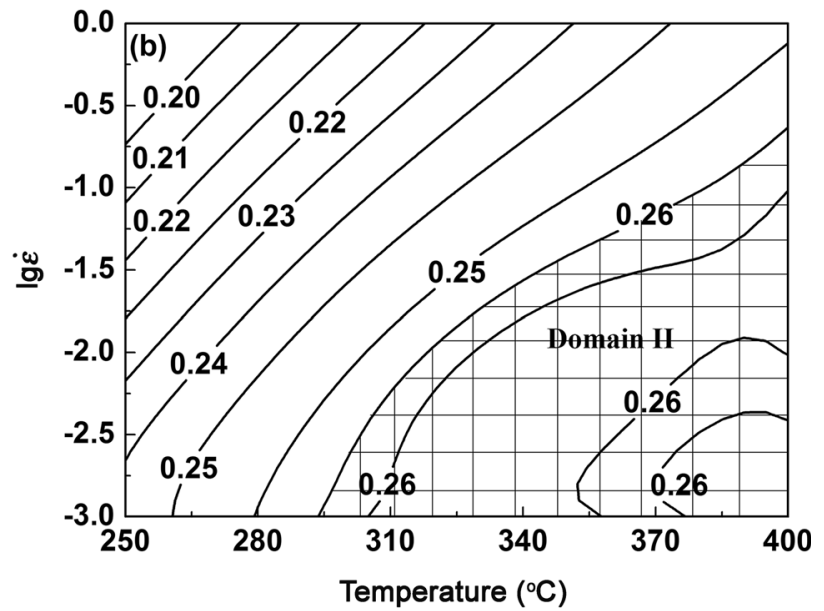


$\frac{Q}{n R}=\left.\frac{\partial \ln [\sinh (\alpha \sigma)]}{\partial(1 / T)}\right|_{\dot{\varepsilon}}$

Substituting Eq. (10) into Eq. (11), it obtains:

$Q=\left.\left.R \cdot \frac{\partial \ln \dot{\varepsilon}}{\partial \ln [\sinh (\alpha \sigma)]}\right|_{T} \cdot \frac{\partial \ln [\sinh (\alpha \sigma)]}{\partial(1 / T)}\right|_{\dot{\varepsilon}}$

In the case of true strain of $0.8, n$ and $Q$ were calculated. Before calculating $n$ and $Q$, firstly the value of $\alpha$ should be determined. In this work, $\alpha$ is determined as 0.0161 , and the details of calculation can be referred to Ref. [25, 26]. According to Eqs. (10) and (11), plots of $\ln \dot{\varepsilon}-$ $\ln [\sinh (\alpha \sigma)]$ and $\ln [\sinh (\alpha \sigma)]-1 / T$ were drawn with the experimental data, as shown in Fig. 4. Then the linear regression is carried out by the least squares method. The straight slope obtained by the regression is the value of $n$ and $Q /(n R)$, respectively. Subsequently, $Q$ is calculated by Eq. (12).

Figure 4 indicates that $n$ increases from 4.8 to 6.6 with increasing deformation temperature. $Q /(n R)$ increases from 2951.0 to 3888.4 with increasing strain rate. Figure 5 shows $n-T$ and $Q /(n R)-\ln \dot{\varepsilon}$ plots, and the adjusted determination coefficient, $R_{\text {adj }}$, from least squares regression is 0.97 and 0.98 , respectively. Thus, $n-T$ and $Q /$ $(n R)-\ln \dot{\varepsilon}$ approximately fit the linear relationship, and the regression equations are:

$n(T)=0.01241 T-1.71274$.

$Q / n R(\ln \dot{\varepsilon})=141.66034 \ln \dot{\varepsilon}+3901.08118$.

Therefore, when the true strain is at $0.8, Q$ can be expressed as a function of $T$ and $\dot{\varepsilon}$ as:

$Q(T, \dot{\varepsilon})=14.61605 T \ln \dot{\varepsilon}+402.5008 T-2017.2036 \ln \dot{\varepsilon}$ $-5.555 \times 10^{4}$.

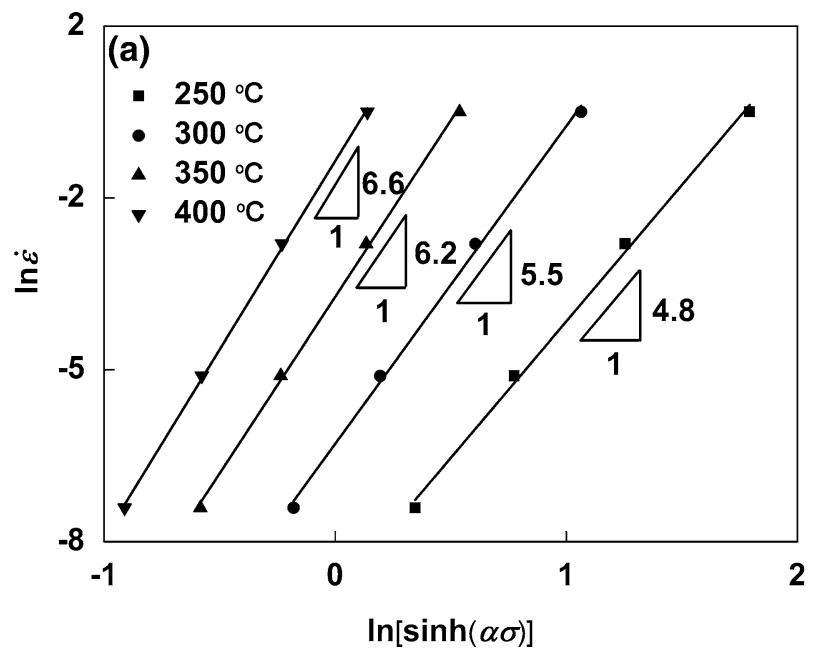

Figure 6 shows contour map of the deformation activation energy over a range of temperature and strain rates where the experiment achieved when the true strain is 0.8 . It can be seen the activation energy increases with increasing temperature and strain rate. The activation energy is $115.7 \mathrm{~kJ} \mathrm{~mol}^{-1}$ at low temperature and low strain rate $\left(250{ }^{\circ} \mathrm{C}, 0.001 \mathrm{~s}^{-1}\right)$ while increases to $214.9 \mathrm{~kJ} \mathrm{~mol}^{-1}$ at high temperature and high strain rate $\left(400{ }^{\circ} \mathrm{C}, 1 \mathrm{~s}^{-1}\right)$.

\subsection{Influence of Strain on $n$ and $Q$}

Similarly, $n$ and $Q$ can be calculated under different strains, in which $n$ is a function of temperature and strain [i.e., $n(T, \varepsilon)]$, and $Q$ is a function of temperature, strain rate and strain [i.e., $Q(T, \dot{\varepsilon}, \varepsilon)]$. Figure 7 shows the three-dimensional and two-dimensional contour maps of stress exponent varying with temperature and strain. In the experimental temperature range, the stress exponent decreases firstly and then increases with increasing strain. In the early stage of deformation (strain is less than 0.2), the stress exponent decreases with increasing temperature, while when the strain is greater than 0.2 , the stress exponent increases with increasing temperature. This indicates that in the early stage of deformation, the flow stress is more sensitive to strain rate. When strain is greater than 0.2 , sensitivity of the flow stress to strain rate reduces. The maximum stress exponent is 7.1 , corresponding to the initial deformation stage under $250^{\circ} \mathrm{C}$, while the minimum stress exponent is 4.3 corresponding to the strain of 0.5 under $250{ }^{\circ} \mathrm{C}$.

Figure 8 shows the variation of the activation energy with temperature, strain and strain rate. When $\varepsilon<0.2, Q$ decreases with increasing $T$ and $\dot{\varepsilon}$. When $\varepsilon>0.2, Q$ increases with increasing $T$ and $\dot{\varepsilon}$. It can be seen the change of $Q$ with $T$ has a same trend as $n$ with $T$, because

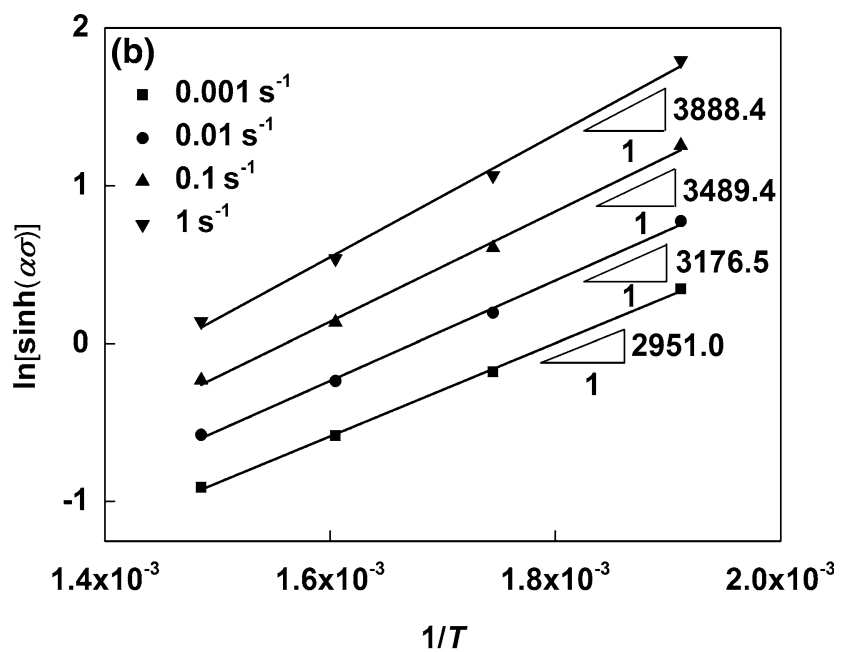

Fig. 4 Determination of $n$ and $Q$ at strain of 0.8 : $\mathbf{a} \ln \dot{\varepsilon}-\ln [\sinh (\alpha \sigma)]$; b $\ln [\sinh (\alpha \sigma)]-1 / T$ 


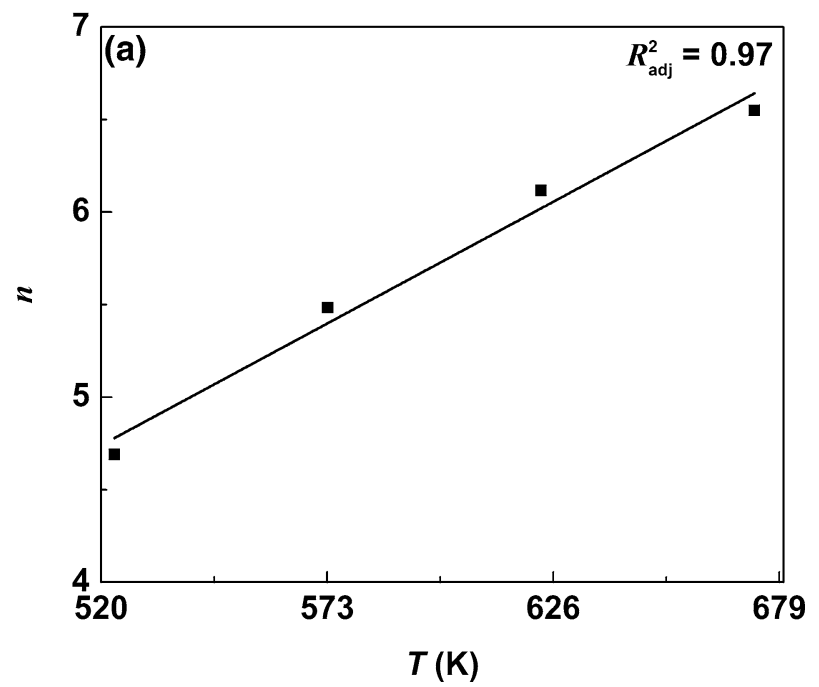

Fig. 5 Relationship plots of $n-T \mathbf{a}, Q /(n R)-\ln \dot{\varepsilon} \mathbf{b}$ at strain of 0.8

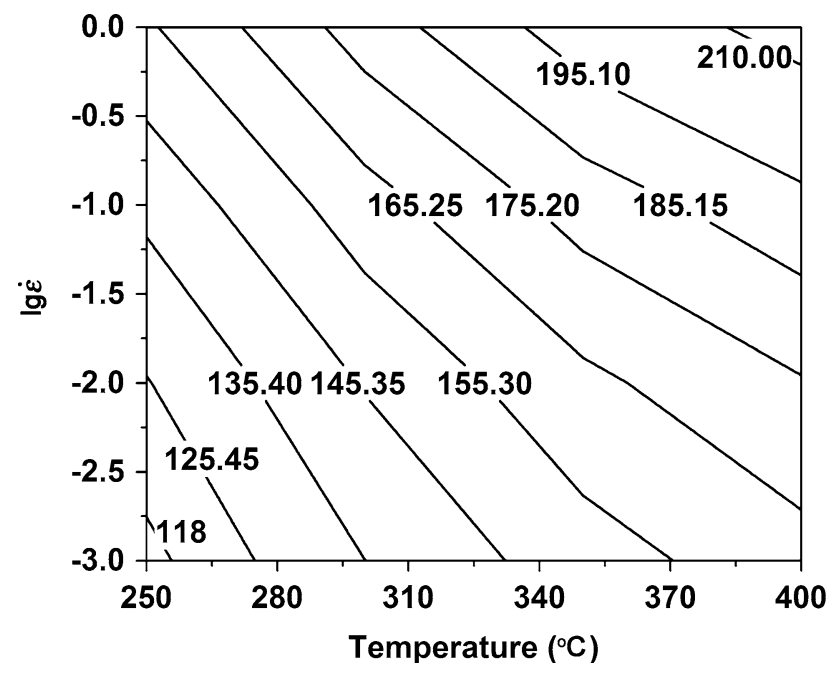

Fig. 6 Relationship between deformation activation energy, temperature and strain rate at strain of 0.8

according to Eq. (13), the change of $Q$ with $T$ comes from the change of $n$ with $T$. The variation of $Q$ with $\dot{\varepsilon}$ is derived from the parameter $Q /(n R)$, which characterizes the sensitivity of $\sigma$ to $T$ at the same $\dot{\varepsilon}$. In the early stage of deformation, $Q$ decreases with the increase in $\dot{\varepsilon}$, which indicates that the sensitivity of $\sigma$ to $T$ decreases with the increasing $\dot{\varepsilon}$. In the late stage of deformation, it behaves oppositely. Regarding the variation of $Q$ with $\varepsilon, Q$ decreases with an increase in strain at a low-temperature range; $Q$ increases firstly and then decreases with the increase in strain at a high temperature and high strain rate regime, while almost has no change at high temperature and low strain rate regime. As shown in Fig. 8, the maximum $Q$ of $220.8 \mathrm{~kJ} \mathrm{~mol}^{-1}$ appears at $400{ }^{\circ} \mathrm{C}$, strain rate of $1 \mathrm{~s}^{-1}$ and the strain of about $0.5-0.7$, which is much higher than the lattice self-diffusion activation energy $\left(135 \mathrm{~kJ} \mathrm{~mol}^{-1}\right.$

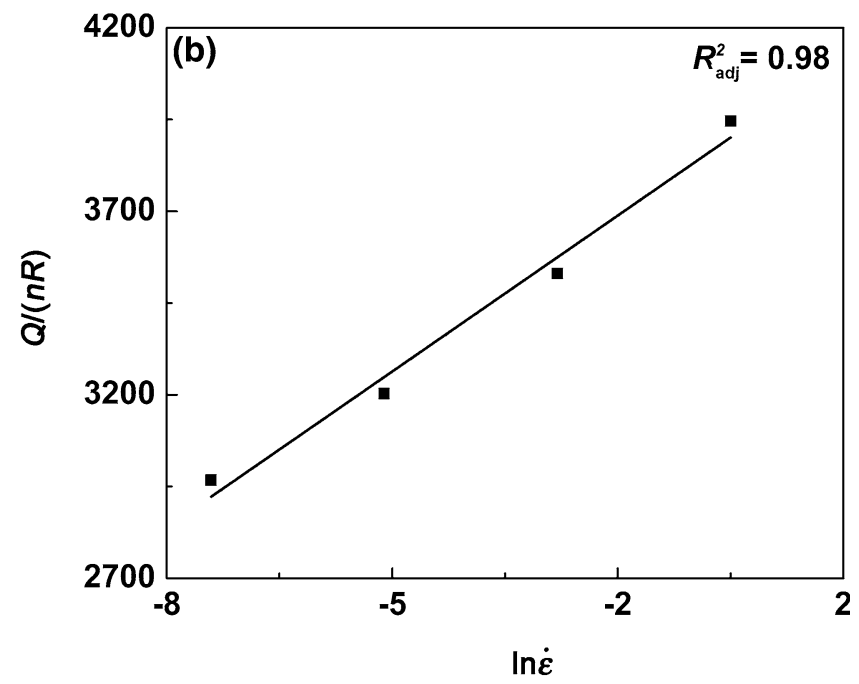

[27]). Minimum $Q$ of $113.6 \mathrm{~kJ} \mathrm{~mol}^{-1}$ is observed at low temperature, low strain rate and the strain of about $0.5-0.7$, which is higher than the grain boundary self-diffusion activation energy (92 $\mathrm{kJ} \mathrm{mol}^{-1}$ [27]).

\section{Analysis and Discussion}

\subsection{Effect of Temperature on Deformation Mechanism and Workability}

Several studies have been carried out on the influence of temperature on the deformation mechanism of $\mathrm{Mg}$ alloys. Most $\mathrm{Mg}$ alloys are of hep structure, having four different slip systems as: (1) basal slip $\{0002\}\langle 11 \overline{2} 0\rangle$, (2) prismatic slip $\{10 \overline{1} 0\}\langle 11 \overline{2} 0\rangle$, (3) first-order pyramidal slip $\{10 \overline{1} 1\}\langle 11 \overline{2} 0\rangle$ and $\{10 \overline{1} 2\}\langle 11 \overline{2} 0\rangle$, and (4) second-order pyramidal slip $\{11 \overline{2} 2\}\langle 11 \overline{2} 3\rangle$. The critical resolved shear stress (CRSS) for these slip systems at room temperature is approximately at a ratio of 1:38:50:100 [28]. The CRSS of basal sip is the lowest at room temperature and does not obviously vary with increasing temperature. Generally, the basal slip can operate at room temperature, but, however, it can only provide two independent slip systems. The CRSSs of non-basal slips are higher, but decrease with increasing temperature [29]. In general, the prismatic slip operates above $177{ }^{\circ} \mathrm{C}$ and significantly improves the ductility of $\mathrm{Mg}$ alloys at a temperature higher than $225^{\circ} \mathrm{C}$ [30]. The first-order pyramidal slip system initiates at a temperature higher than $350{ }^{\circ} \mathrm{C}$ [31], and the second-order pyramidal slip system activates extensively at a temperature higher than $400{ }^{\circ} \mathrm{C}$ [32].

Taking the steady-state flow for example, at a strain rate of $0.001 \mathrm{~s}^{-1}$, when temperature undergoes from $250{ }^{\circ} \mathrm{C}$ up 


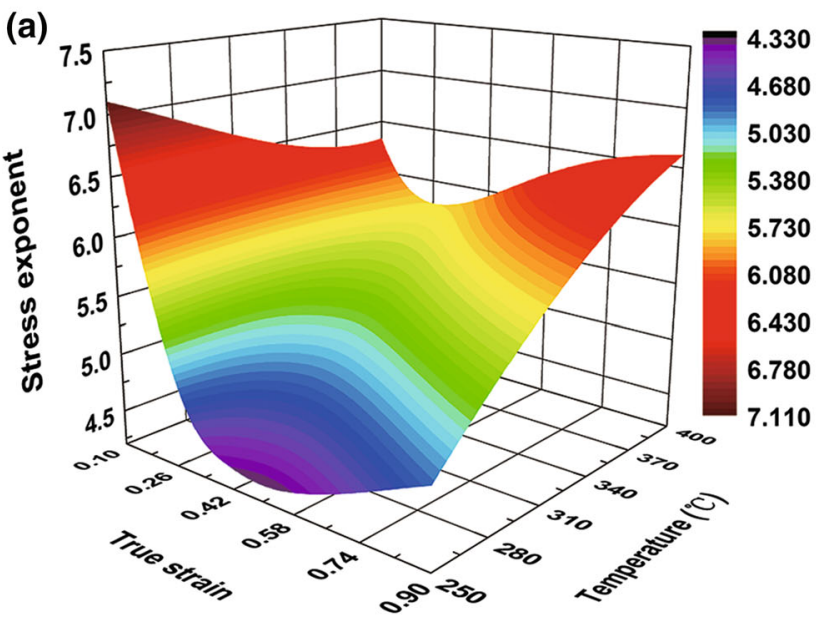

Fig. 7 3D a, 2D b maps of variation of $n$ with $T$ and $\varepsilon$
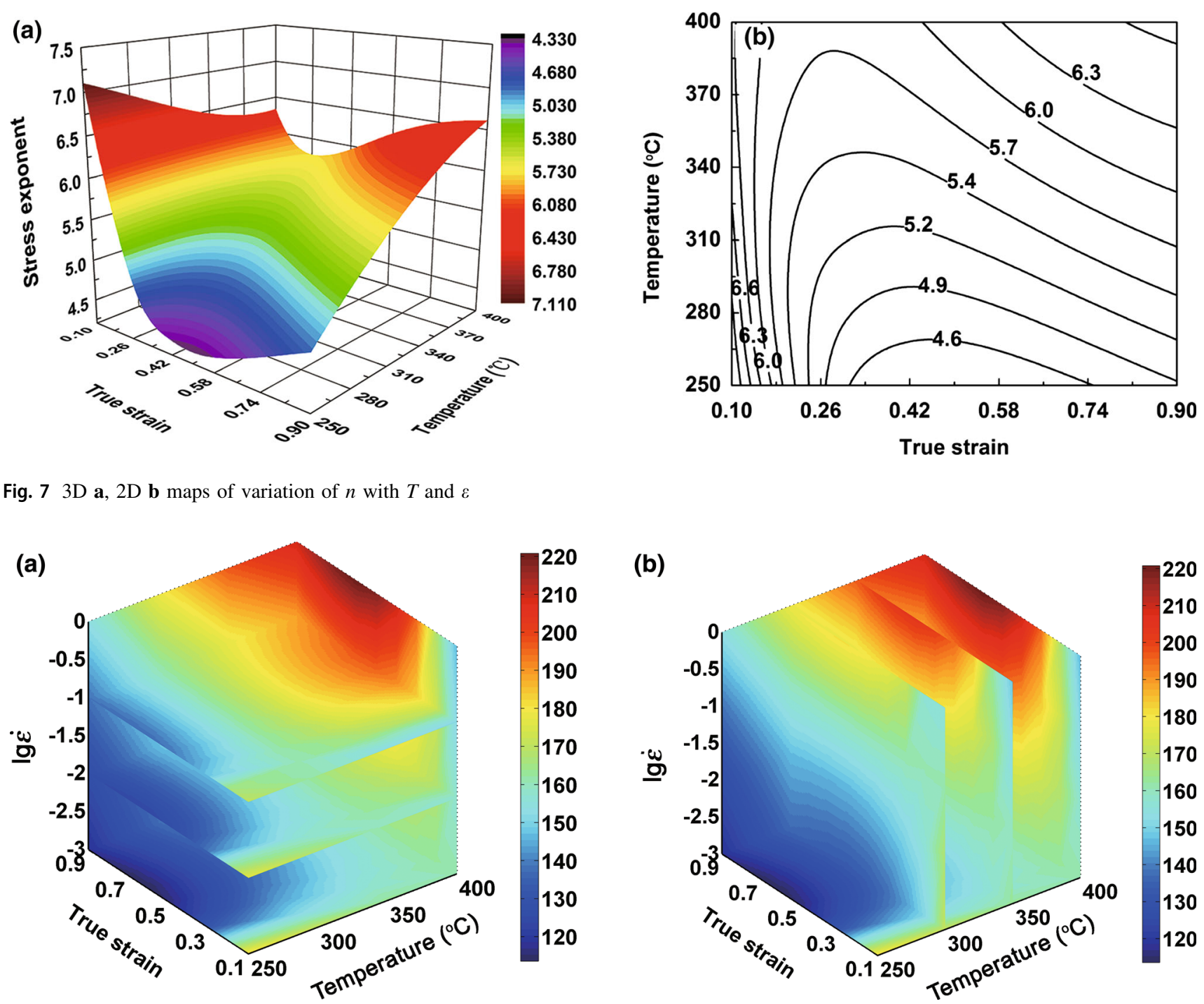

Fig. 8 Variation of $Q$ with $T, \varepsilon$ and $\dot{\varepsilon}$ : a $Q$ at strain rates of $0.001,0.01$ and $0.1 \mathrm{~s}^{-1} ; \mathbf{b} Q$ at temperatures of 300,350 and $400{ }^{\circ} \mathrm{C}$

to $400{ }^{\circ} \mathrm{C}$, the stress exponent increases from 4.8 to 6.6 (Fig. 7), the activation energy increases from 115.7 to $161.6 \mathrm{~kJ} \mathrm{~mol}^{-1}$ (Fig. 8), and the efficiency of power dissipation increases from 0.22 to 0.24 (Fig. 3). At $250{ }^{\circ} \mathrm{C}$, value of $n$ is 4.8 and that of $Q$ is $115.7 \mathrm{~kJ} \mathrm{~mol}^{-1}$, close to the lattice self-diffusion activation energy of $\mathrm{Mg}$ alloys. This indicates that the deformation mechanism is dominated by basal and prismatic slip systems, while the ratecontrolling mechanism is the thermally activated climb of edge dislocation [31]. Due to the low stacking fault energy of basal and prismatic planes $\left(45 \mathrm{~mJ} \mathrm{~m}^{-2}\right.$ [33] and 60-78 $\mathrm{mJ} \mathrm{m}^{-2}$ [34], respectively), dislocation climbing or cross-slip is inhibited [35] and DRX nucleation is delayed. Figure 9a shows the microstructure of $\mathrm{Mg}$ alloy AZ31 when it reached the deformation strain of 0.8 with the strain rate of $0.001 \mathrm{~s}^{-1}$ at $250{ }^{\circ} \mathrm{C}$. It can be seen there are a large number of fine recrystallized grains appearing at the grain boundaries of the initial coarse grains, and the average size of the DRX grain is only $5.5 \mu \mathrm{m}$. However, the recrystallization is not yet completed as a result of low grain boundary migration rate at $250{ }^{\circ} \mathrm{C}$ and a strong pinning effect from the plentiful second phase in Fig. $9 \mathrm{~b}$. Similar results are also given in Ref. [36, 37]. The microstructure observation is in agreement with the prediction from processing map.

When temperature rises above $350{ }^{\circ} \mathrm{C}, \quad n>6.0$, $Q>150 \mathrm{~kJ} \mathrm{~mol}^{-1}$, abundant pyramidal slip systems start to operate, which means that the dominate deformation mechanism of AZ31 becomes cross-slip. Since pyramidal slip alone can provide five independent slip systems to better coordinate the deformation in different directions, the deformation capacity of $\mathrm{Mg}$ alloys improves. Meanwhile, the pyramidal plane has higher stacking fault energy of $173 \mathrm{~mJ} \mathrm{~m}^{-2}$ [38], favoring cross-slip of dislocation and 

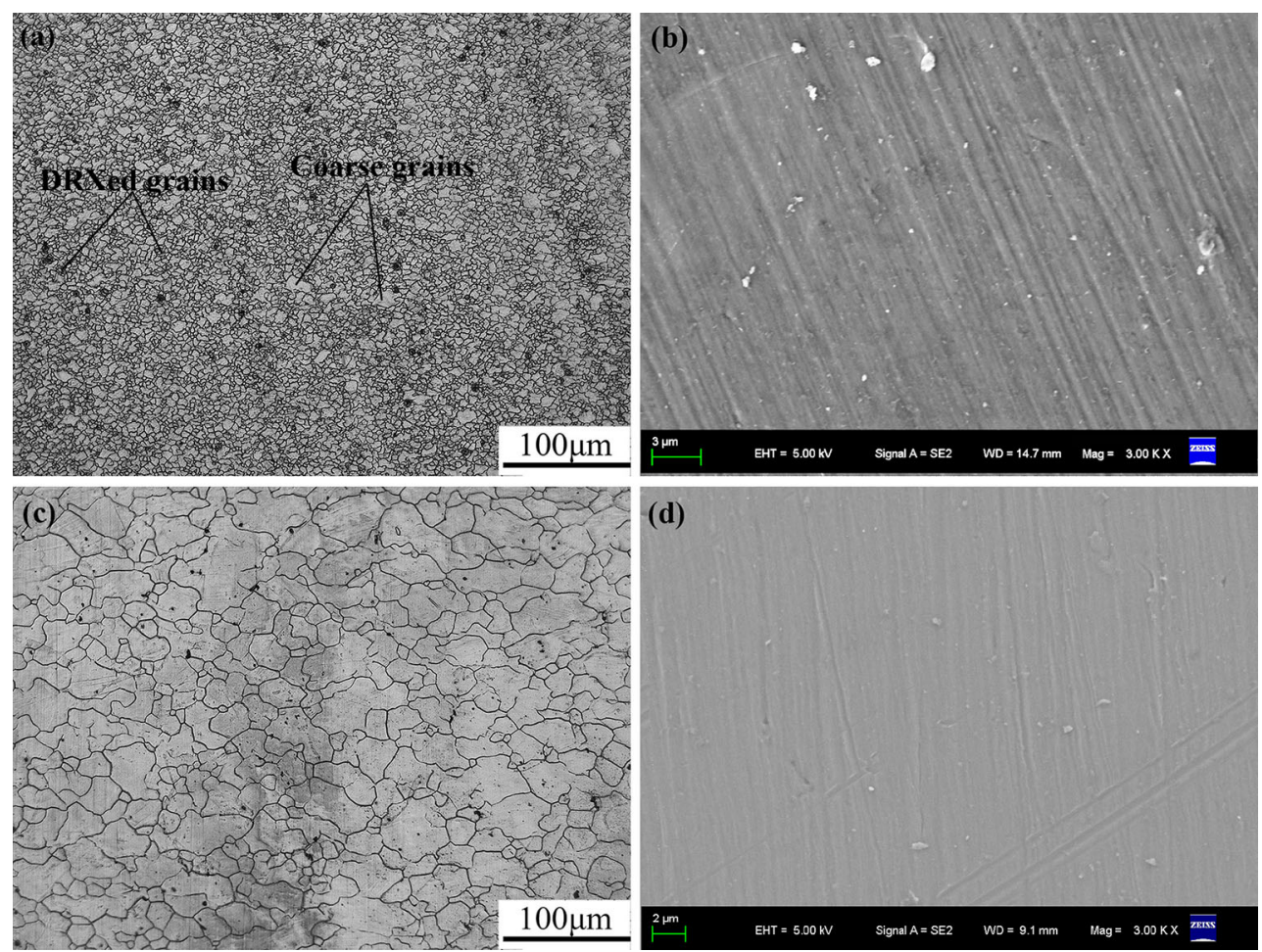

Fig. 9 OM a, c, SEM b, d images of AZ31 alloy deformed at $250{ }^{\circ} \mathrm{C}, 0.001 \mathrm{~s}^{-1} \mathbf{a}, \mathbf{b}, 400{ }^{\circ} \mathrm{C}, 0.001 \mathrm{~s}^{-1} \mathbf{c}, \mathbf{d}$

DRX nucleation [39]. In addition, grain boundary migration rate is higher at higher temperature, and the pinning effect of second phase on grain boundary is reduced due to its dissolution into the matrix as shown in Fig. 9d. All these contribute to a rather full development of DRX as temperature is higher than $350{ }^{\circ} \mathrm{C}$. Figure $9 \mathrm{c}$ shows the microstructure of $\mathrm{Mg}$ when it reached a deformation strain of 0.8 with a strain rate of $0.001 \mathrm{~s}^{-1}$ at $400{ }^{\circ} \mathrm{C}$. The typical zigzag grain boundary indicates the onset of DRX, and it can be clearly seen that DRX has been basically completed with a uniform grain size $(25.7 \mu \mathrm{m}$ on average) distribution. Therefore, with increasing temperature, non-basal slip starts to operate and the recrystallization carries out more completely, which can improve the plastic deformation capacity of Mg alloy AZ31.

\subsection{Effect of Strain Rate on Deformation Mechanism and Workability}

The effect of strain rate on deformation mechanism and workability is complex, and it shows different tendency at varying temperatures. In general, the deformation activation energy increases and the efficiency of power dissipation decreases with an increasing strain rate. At a hightemperature region beyond $350{ }^{\circ} \mathrm{C}$ where excellent plastic deformation capacity is apparent, the strain rate has a trivial impact on the deformation mechanism and microstructure evolution. At $400{ }^{\circ} \mathrm{C}$ for instance, when the strain rate increases from 0.001 to $1 \mathrm{~s}^{-1}, n$ is 6.6 and $Q$ increases from 161.6 to $219.1 \mathrm{~kJ} \mathrm{~mol}^{-1}$. This means that the dominant deformation mechanism of AZ31 is cross-slip of dislocation which is independent of strain rate at such a high-temperature region. On the one hand, cross-slip can effectively increase the number of the independent slip systems, and on the other hand, benefits the dynamic recovery and DRX nucleation, both of which contribute to stress release and thus superior plastic deformation for $\mathrm{Mg}$ alloys is seen at high-temperature region.

At a low-temperature region below $350{ }^{\circ} \mathrm{C}$, the strain rate has an obvious influence on the deformation mechanism and microstructure evolution. Take the temperature of $250{ }^{\circ} \mathrm{C}$ for instance. When the strain rate increases from 0.001 to $1 \mathrm{~s}^{-1}, n$ is 4.8 and $Q$ increases from 115.7 to $153.9 \mathrm{~kJ} \mathrm{~mol}^{-1}$. This indicates that the deformation mechanism transfers from basal slip and prismatic slip accompanied with a small amount of cross-slip at a low strain rate to cross-slip at a high strain rate. As mentioned above, basal slip and thermal-activated prismatic slip dominate at $250{ }^{\circ} \mathrm{C}$. According to the Von Mises principles, at least five independent slip systems are required for uniform deformation. However, basal slip and prismatic slip can only provide four independent slip systems, which 
cannot satisfy the Von Mises principles. Thus, to achieve good and uniform plastic deformation, a small amount of cross-slip or twinning and other deformation mechanism should be activated. A low strain rate provides insufficient time to atoms for diffusion, and thus, partial stress is dissipated through dislocation gliding and climbing. Meanwhile, there is sufficient time for the development of DRX at the low strain rate, which also benefits the release of stress, as shown in Fig. 9a [40, 41]. As the strain rate increases, a large number of dislocations accumulate at the grain boundary, resulting in a high degree of stress concentration, so stress-assisted cross-slip appears in the vicinity of the grain boundary [42]. Cross-slip contributes to DRX nucleation, and thus, a typical necklace-like microstructure is observed at grain boundary (as shown in Fig. 10a). SEM morphology in Fig. 10b indicates that a large amount of second-phase particles exist in the sample, which aggravates the inhomogeneous deformation and induces the flow localization at high strain rates due to accumulation of moving dislocations around them [43]. At the same time, DRX grain size is less than $10 \mu \mathrm{m}$ at high strain rates. According to previous study, cross-slip can pass through entire grains with a small size [44], so slip is the dominant deformation mechanism, while a small amount of grain boundary slip (GBS) can also occur in the fine-grained materials [45]. In addition, as strain rate increases, the efficiency of power dissipation decreases from 0.22 at a strain rate of $0.001 \mathrm{~s}^{-1}$ to 0.19 at a strain rate of $1 \mathrm{~s}^{-1}$, which is consistent with the decreasing recrystallization fraction observed in Fig. 10.

\subsection{Effect of Strain on Deformation Mechanism and Workability}

The effect of strain on deformation mechanism and machinability is also complex. According to the processing map in Fig. 3, two characteristic deformation conditions $\left(250{ }^{\circ} \mathrm{C}, 1 \mathrm{~s}^{-1}\right.$ and $\left.400{ }^{\circ} \mathrm{C}, 0.001 \mathrm{~s}^{-1}\right)$ in flow instability domain (Domain I) and peak efficiency domain (Domain
II) were selected to analyze the effect of strain on the deformation mechanism and hot workability.

Under $250{ }^{\circ} \mathrm{C}, 1 \mathrm{~s}^{-1}$, flow instability mainly occurs at the early stage of deformation, i.e., work hardening stage. Figure 11 shows the microstructure of specimen deformed at $250{ }^{\circ} \mathrm{C}, 1 \mathrm{~s}^{-1}$ to the strain of 0.2 where twins and cracking are observed. At the strain of 0.8 , the number of twins decreases significantly and DRX grains are found around grain boundaries as shown in Fig. 10. Figure 12 displays varying $n, Q$ and $\eta$ with strain. Under $250{ }^{\circ} \mathrm{C}$, $1 \mathrm{~s}^{-1}, Q$ has slight changes with increasing strain, which is $164.0 \mathrm{~kJ} \mathrm{~mol}^{-1}$ at the beginning and decreases to $154.0 \mathrm{~kJ} \mathrm{~mol}^{-1}$ at the end as shown in Fig. 12a. In Fig. 12b, $n$ (marked with solid symbols in Fig. 12b) first decreases and then increases, from 7.1 at the beginning to a minimum value of 4.4 and then to 5.0 at the end of deformation. Meanwhile, $\eta$ (marked with blank symbols in Fig. 12b) increases first and then decreases. Interestingly, the variations of $n$ and $\eta$ are exactly opposite and the strains for the trough are similar to that for the peak. This also

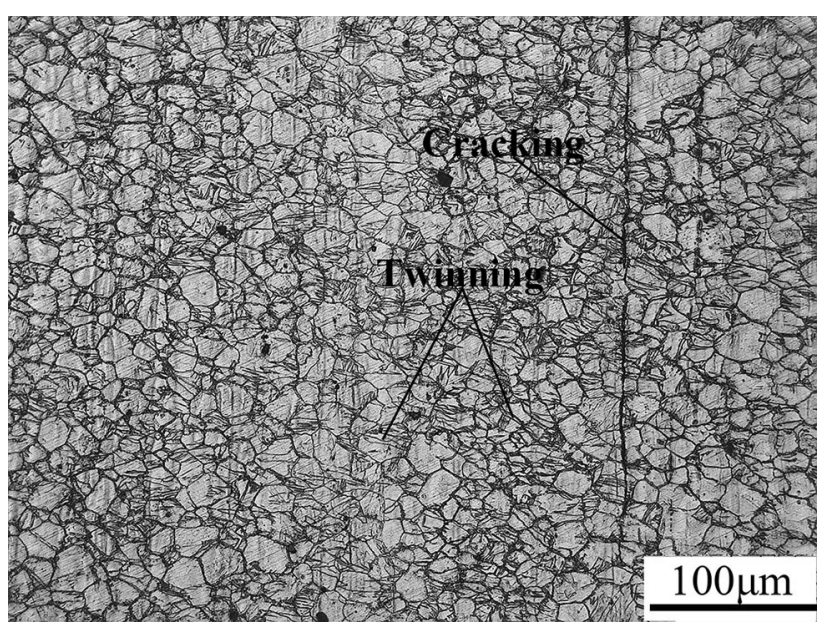

Fig. 11 Microstructure of AZ31 alloy deformed at $250{ }^{\circ} \mathrm{C}, 1 \mathrm{~s}^{-1}$ at strain of 0.2
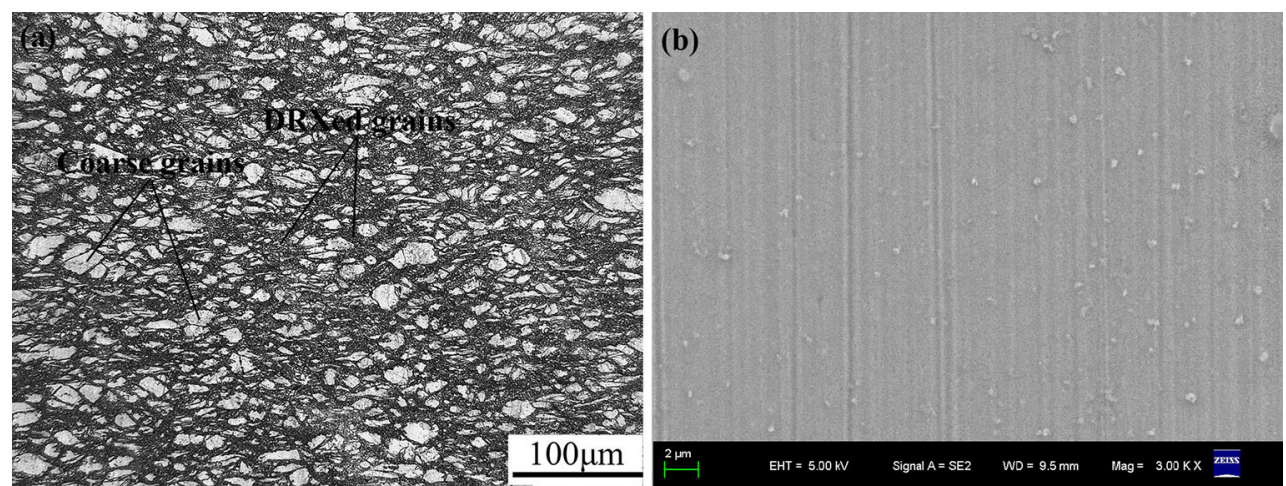

Fig. 10 OM a, SEM b images of AZ31 alloy deformed at $250{ }^{\circ} \mathrm{C}, 1 \mathrm{~s}^{-1}$ at strain of 0.8 

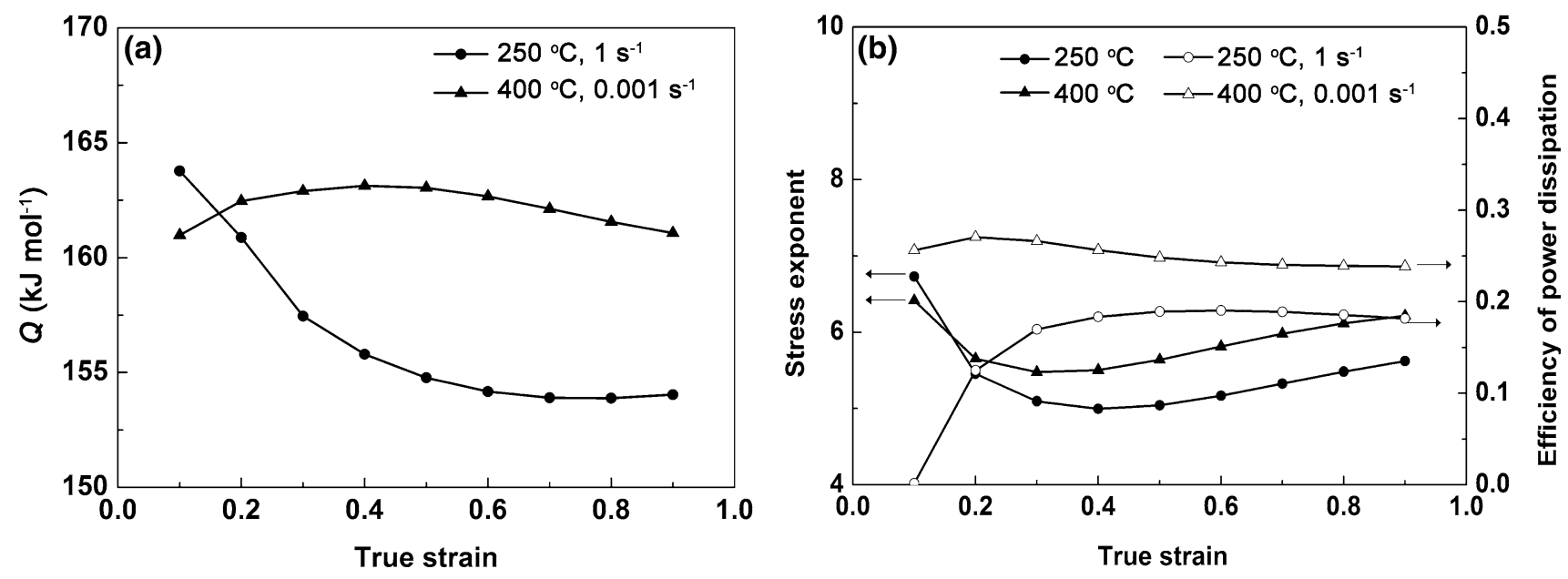

Fig. 12 Variation of $Q, n \mathbf{a}, \eta \mathbf{b}$ with true strain

exhibits the effects of work hardening and dynamic softening on the flow stress characteristics. According to the values of $n$ and $Q$, the dominant deformation mechanism at the beginning of deformation is cross-slip of screw dislocation [46]. Due to the high level of strain rate, the stress concentration around the grain boundary has little time to release and will be relaxed by crack initiation and propagation. Thus, flow instability occurs as shown in Fig. 11. Since the cross-slip promotes the DRX nucleation while grain boundary migration rate is low at low temperature, DRX grains size is only about $1.3 \mu \mathrm{m}$. With an increase in strain, DRX fraction increases and GBS is prone to occur in this fine-grained area. This may be responsible for the slight decrease in $Q$ at the late stage of deformation since the $Q$-value for GBS is only $92 \mathrm{~kJ} \mathrm{~mol}^{-1}$.

Select the $400{ }^{\circ} \mathrm{C}, 0.001 \mathrm{~s}^{-1}$ in the peak efficiency of power dissipation domain for analysis. With the increase in strain, $Q$ has no obvious change and remains at about $162.0 \mathrm{~kJ} \mathrm{~mol}^{-1}$. $n$ firstly decreases from 6.3 to the minimum value of 5.8 and then gradually increases to 6.6 , while $\eta$ slightly increases and then slowly decreases to around 0.25 . The values of $Q$ and $n$ demonstrate that the dominate deformation mechanism in this region is cross-slip of screw dislocation, which does not change as the strain increases [13].

\section{Conclusions}

Based on the experimental flow stress curves, the processing map, stress exponent and activation energy of $\mathrm{Mg}$ alloy AZ31 were calculated. The intrinsic relationships between the deformation mechanism, microstructure evolution and hot workability were established. The following conclusions were drawn:

1. With the increase in deformation temperature, independent slip system increases due to the operation of prismatic slip and pyramidal slip; meanwhile, the enhanced dynamic softening buffers the stress concentration at grain boundaries, both of which account for the improvement of deformation capability.

2. The effect of strain rate is complex. In the hightemperature region higher than $350{ }^{\circ} \mathrm{C}$, the dominant deformation mechanism of AZ31 is cross-slip and DRX can be fully developed. Thus, good plastic deformation capability is achieved, which is independent of strain rate. In contrast, in the temperature region lower than $350{ }^{\circ} \mathrm{C}$, the deformation mechanism is basal slip and the prismatic slip, accompanied by a small amount of cross-slip at low strain rate, and it is transformed to cross-slip at high strain rate. The highly concentrated stress due to the difference in CRSS and inadequate development in DRX results in weakened ductility of AZ31 alloy.

3. The effect of strain is also complicated. At the peak efficiency of power dissipation regime (e.g., $400{ }^{\circ} \mathrm{C}$, $0.001 \mathrm{~s}^{-1}$ ), deformation mechanism and hot workability of AZ31 are insensitive to the strain. The dominant deformation mechanism is dislocation cross-slip, and sufficient dynamic softening is achieved due to the fast rate of DRX nucleation and grain growth. At the flow instability regime (e.g., $250{ }^{\circ} \mathrm{C}, 1 \mathrm{~s}^{-1}$ ), the dominant deformation mechanism is transformed from the crossslip at lower strain to the cross-slip accompanied with a small amount of GBS at higher strain. The stress 
concentration at grain boundary may be responsible for the onset of flow instability.

Acknowledgements This work was supported financially by the National Key Research and Development Program of China (No. 2016YFC1102402), the National Natural Science Foundation of China (No. 31570961) and the Natural Science Foundation of Jiangsu Province (No. BK20160968).

\section{References}

[1] K. Liu, X.H. Dong, H.Y. Xie, F. Peng, Mater. Sci. Eng., A 623, 97 (2015)

[2] S. Housh, B. Mikucki, A. Stevenson, Selection and application of magnesium and magnesium alloys, 10th edn. (ASM International, Materials Park, OH, 1990), p. 455

[3] W.L. Cheng, Q.W. Tian, H. Yu, B.S. You, H.X. Wang, Mater. Des. 85, 762 (2015)

[4] W.L. Cheng, Z.P. Que, J.S. Zhang, C.X. Xu, W. Liang, B.S. You, S.S. Park, Int. J. Miner. Metall. Mater. 20, 49 (2013)

[5] K.R. Athul, U.T.S. Pillai, A. Srinivasan, B.C. Pai, Adv. Eng. Mater. 18, 770 (2016)

[6] P. Zhou, Q.X. Ma, Acta Metall. Sin. (Engl. Lett.) 30, 907 (2017)

[7] J. Han, J.P. Sun, Y. Han, H. Liu, Acta Metall. Sin. (Engl. Lett.) 30, $1080(2017)$

[8] G.Z. Quan, H.R. Wen, J. Pan, Z.Y. Zou, Int. J. Precis. Eng. Manuf. 17, 171 (2016)

[9] Y.Y. Dong, C.S. Zhang, G.Q. Zhao, Y.J. Guan, A.J. Gao, W.C. Sun, Mater. Des. 92, 983 (2016)

[10] Y. Zhang, H.L. Sun, A.A. Volinsky, B.H. Tian, Z. Chai, P. Liu, Y. Liu, Acta Metall. Sin. (Engl. Lett.) 29, 422 (2016)

[11] C. Poletti, H. Dieringa, F. Warchomicka, Mater. Sci. Eng., A 516, 138 (2009)

[12] Y.V.R.K. Prasad, K.P. Rao, Mater. Des. 30, 3723 (2009)

[13] Y.V.R.K. Prasad, K.P. Rao, Mater. Sci. Eng., A 487, 316 (2008)

[14] N. Srinivasan, Y.V.R.K. Prasad, P.R. Rao, Mater. Sci. Eng., A 476(1-2), 146 (2008)

[15] W.P. Peng, P.J. Li, P. Zeng, L.P. Lei, Mater. Sci. Eng., A 494(1-2), 173 (2008)

[16] Y.C. Lin, F.Q. Nong, X.M. Chen, D.D. Chen, M.S. Chen, Vacuum 137, 104 (2017)

[17] G.A. He, L.M. Tan, F. Liu, L. Huang, Z.W. Huang, L. Jiang, Materials 10, 161 (2017)

[18] Y.V.R.K. Prasad, H.L. Gegel, S.M. Doraivelu, J.C. Malas, J.T. Morgan, K.A. Lark, D.R. Barker, Metall. Trans. A 15, 1883 (1984)

[19] Z.Y. Jin, N.N. Li, K. Yan, J.X. Chen, D.L. Wei, Z.S. Cui, Acta Metall. Sin. (Engl. Lett.) (2017). https://doi.org/10.1007/s40195017-0669-1
[20] P. Dadras, J.F. Thomas, Metall. Trans. A 12, 1867 (1981)

[21] S.V.S.N. Murty, M.S. Sarma, B.N. Rao, Metall. Mater. Trans. A 28, 1581 (1997)

[22] S.V.S.N. Murty, B.N. Rao, B.P. Kashyap, Mater. Process. Technol. 166, 279 (2005)

[23] Y.V.R.K. Prasad, K.P. Rao, S. Sasidhara, Hot working guide: a compendium of processing maps, 2nd edn. (ASM International, Materials Park, $\mathrm{OH}, 2015)$, p. 13

[24] C.M. Sellars, W.J.M. Tegart, Int. Metall. Rev. 17, 1 (1972)

[25] D.G. He, Y.C. Lin, M.S. Chen, J. Chen, D.X. Wen, X.M. Chen, J. Alloys Compd. 649, 1075 (2015)

[26] Y.P. Li, R.B. Song, E.D. Wen, F.Q. Yang, Acta Metall. Sin. (Engl. Lett.) 29, 441 (2016)

[27] H.J. Frost, M.F. Ashby, Deformation mechanism maps: the plasticity and creep of metals and ceramics (Pergamon Press, Oxford, 1982), p. 44

[28] R. Gehrmann, M.M. Frommert, G. Gottstein, Mater. Sci. Eng., A 395, 338 (2005)

[29] H. Yoshinaga, R. Horiuchi, Trans. Jpn. Inst. Metals 5, 14 (1964)

[30] P.W. Flynn, J. Mote, J.E. Dorn, Trans. Metall. Soc. AIME 221, 1148 (1961)

[31] Y.V.R.K. Prasad, K.P. Rao, Mater. Sci. Eng., A 432, 170 (2006)

[32] T. Obara, H. Yoshinga, S. Morozumi, Acta Metall. 21, 845 (1973)

[33] Z. Feng, X. Zhang, F. Pan, Rare Metal. Mater. Eng. 41, 1765 (2012)

[34] D.H. Sastry, Y.V.R.K. Prasad, K.I. Vasu, Scr. Metall. 3, 927 (1969)

[35] M.H. Yoo, S.R. Agnew, J.R. Morris, K.M. Ho, Mater. Sci. Eng., A 319, 87 (2001)

[36] D.X. Wen, Y.C. Lin, Y. Zhou, Vacuum 141, 316 (2017)

[37] Z.Y. Jin, D.H. Yu, X.T. Wu, K. Yin, K. Yan, J. Mater. Sci. Technol. 32, 1260 (2016)

[38] J.R. Morris, J. Scharff, K.M. Ho, D.E. Turner, Y.Y. Ye, M.H. Yoo, Philos. Mag. A 76, 1065 (1997)

[39] J. Koike, T. Kobayashi, T. Mukai, H. Watanabe, M. Suzuki, K. Maruyama, K. Higashi, Acta Mater. 51, 2055 (2003)

[40] D.D. Chen, Y.C. Lin, Y. Zhou, M.S. Chen, D.X. Wen, J. Alloys Compd. 708, 938 (2017)

[41] Z.H. Zhou, Q.C. Fan, Z.H. Xia, A.G. Hao, W.H. Yang, W. Ji, H.Q. Cai, J. Mater. Sci. Technol. 33, 637 (2017)

[42] F. Berge, L. Krüger, H. Ouaziz, C. Ullrich, Trans. Nonferrous Met. Soc. China 25, 1 (2015)

[43] D.X. Wen, Y.C. Lin, J. Chen, J. Deng, X.M. Chen, J.L. Zhang, M. He, Mater. Sci. Eng., A 620, 319 (2015)

[44] J. Koike, Mater. Sci. Forum 419, 189 (2003)

[45] J. Koike, R. Ohyama, T. Kobayashi, M. Suzuki, K. Maruyama, Mater. Trans. 44, 445 (2005)

[46] H.Y. Wu, C.T. Wu, J.C. Yang, M.J. Lin, Mater. Sci. Eng., A 607, 261 (2014) 